\title{
MUTACIONES ESPACIALES PRODUCIDAS POR EL TURISMO EN EL MUNICIPIO DE TORREVIEJA
}

\author{
José Fernando Vera Rebollo
}

\footnotetext{
*Nuestro agradecimiento a D. Joaquín García Sánchez, Concejal de Urbanismo, así como al resto de la Corporación Municipal y administrativos del Ayuntamiento de Torrevieja.
}

\section{INTRODUCCIÓN}

El término turismo resulta ambiguo en una primera aproximación debido a que abarca acepciones diferentes. Dentro del objeto de la Geografía del turismo interesa fundamentalmente el conocimiento de las relaciones entre la tierra y el hombre desde el punto de vista de los fenómenos turísticos, lo que en definitiva viene a ser la organización del espacio turístico, cuyo rasgo más representativo es la concentración a lo largo de la franja litoral, un espacio escaso y frágil, como un yacimiento a explotar, donde concurren fuerzas antagónicas y en el que las actividades más rentables acaban rechazando a las menos organizadas en el juego del mercado, tal y como señala Michaud².

El análisis del hecho turístico en el municipio de Torrevieja pone de relieve el proceso de configuración de un espacio turístico, surgido del veraneo tradicional, al que se añade en clara oposición el turismo residencial masificado.

\section{FACTORES QUE HAN DETERMINADO LA APARICIÓN Y DESARROLLO DEL NÚCLEO TURÍSTICO}

La aparición y evolución posterior de Torrevieja como núcleo turístico está determinada esencialmente por cuatro factores: [116]

\footnotetext{
${ }^{1}$ REYNAUD, A.: «Elements pour une épistémologie de la géographie du tourisme», Travaux de l'Institut de Géographie de Reims, n. ${ }^{\circ} 23-24,1975$, pág. 11.

${ }^{2}$ MICHAUD, J. L.: La ordenación de las zonas litorales, Madrid, I.E.A.L., 1981, pág. 33.
} 


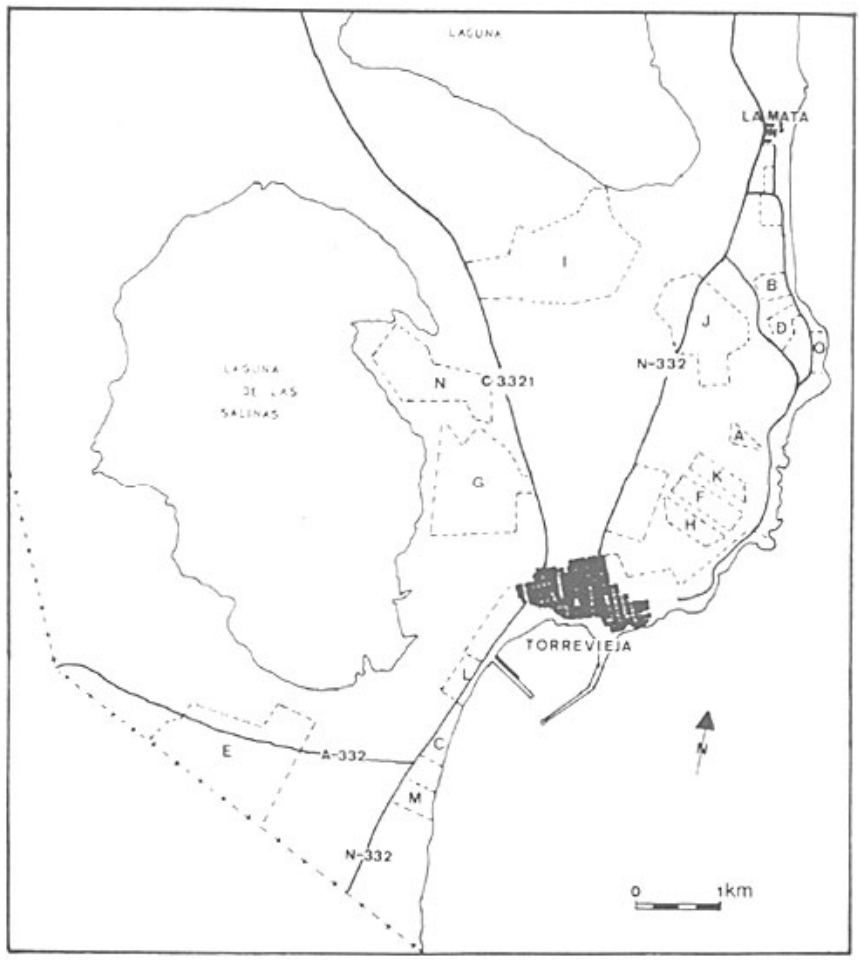

FIGURA 1. Localización de las urbanizaciones más importantes del término municipal: A, Villa Sol (1965); B, Molino Blanco (1967); C, La Veleta (1967); D, Lomas del Mar (1968); E, Los Balcones (1968); F, Los Ángeles (1972); G, La Torreta (1974); H, Calas Blancas (1974); I, El Chaparral (1974); J, Aguas Nuevas (1974); K, La Casa de La Primavera (1977); L, Mediterráneo (1979); M, Mar Azul (1979); N, La Torreta III (1979); O, Cabo Cervera (1982). [117]

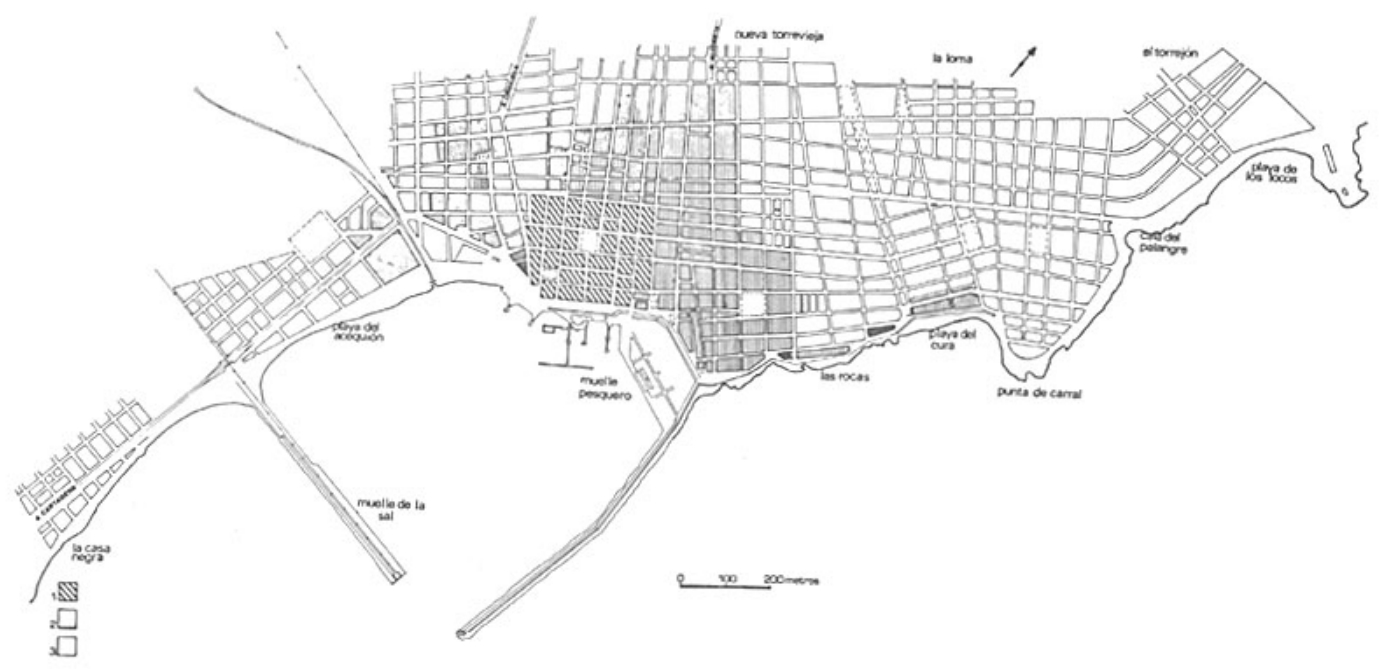


FIGURA 2. Evolución urbana de Torrevieja (1829-1982): 1, sector reconstruido tras el terremoto de 1829 (ingeniero Larramendi); 2, construido entre mediados del siglo XIX y 1956; 3, construido entre 1956 y 1982. [118]

1) El medio físico.- Es el menos importante de estos factores, ya que si bien la influencia del mar determina la suavidad invernal (media de enero de $10,1^{\circ} \mathrm{C}$ ) y las temperaturas agradables del verano (media de $25,5^{\circ} \mathrm{C}$ en agosto), el lugar no ha ofrecido grandes atractivos naturales para el turismo, sobre todo si se compara con algún núcleo próximo que, paradójicamente, no ha tenido importancia como lugar de veraneo hasta fechas recientes.

El término municipal de Torrevieja se extiende por el litoral alicantino los aproximadamente diez kilómetros comprendidos entre las dunas de Guardamar, por la parte septentrional, y Punta Prima (Orihuela) por la meridional. Se trata de un reducido sector costero donde se alternan diversos subtipos de litoral. De acuerdo con la clasificación realizada por Rosselló ${ }^{3}$, en el límite septentrional aparece el subtipo B-1, playas de arena con extensas formaciones dunares, algunas móviles, que continúan el conjunto de dunas de Guardamar hasta el Cabo Cervera, lugar en el que aparece el subtipo A-2, caracterizado por la presencia de un acantilado medio-bajo que se prolonga hasta Punta Cornuda interferido a veces por pequeñas calas, debidas a la acción de las ramblas que realizan una intensa deposición de arena y cantos.

Algo más al sur, a continuación del canal del Acequión, que comunica la laguna de las salinas con el mar, aparece un nuevo subtipo de litoral, ya que las lagunas de Torrevieja y La Mata son casos peculiares dentro de las lagunas litorales, con diferencias, según parece, del resto de las albuferas valencianas, debido a que en la formación de las referidas lagunas intervino la tectónica. Una banda, eutirrenyense en superficie y, probablemente, antigua restinga, separa las lagunas del mar y determina desde el tirrenyense una depresión cerrada. Ambas formaciones lagunares quedan divididas por el alto gravimétrico de el Torrejón y su periferia la constituyen glacis tendidos que biselan el Plioceno superior.

Las playas constituyen el recurso turístico más importante y, en este sentido, son varias las que aparecen en el referido sector litoral, desde la denominada playa de La Mata en los confines septentrionales del municipio, ceñida por un extenso cordón dunar, como ya se ha señalado, hasta las menos extensas de Los Locos y El Cura, flanqueadas por puntas y, más al mediodía, la antigua playa que desapareció con el relleno del muelle pesquero, continuada por la del Acequión.

2) El área de atracción.- Importante es destacar la trascendencia que para el desarrollo del turismo tiene la proximidad de una serie de núcleos poblacionales de carácter rural como Murcia, Orihuela, Callosa del Segura, etc..., cuyos propietarios agrarios sienten la atracción del veraneo en un lugar de fácil acceso.

La evolución del veraneo tradicional estaba determinada en gran parte por [119] las condiciones de la economía agraria en los referidos núcleos, hasta el punto de que los mejores años agrícolas tenían su reflejo en la temporada de baños de Torrevieja, ya que junto al turismo selectivo que formaba la colonia veraniega también acudía una muchedumbre de la clase baja los días festivos.

3) Los balnearios.- Han sido uno de los factores más importantes del veraneo tradicional, con un período de auge hasta la Guerra Civil, si bien su importancia siguió siendo considerable hasta el desarrollo del turismo de masas en el decenio de 1960. En la década de 1920-30 llegaron a contarse siete establecimientos de baños: cuatro en la playa donde hoy se ubica el Club Náutico, uno en el sector cubierto por el relleno del puerto (playa de los bloques) y dos en El Acequión. Cuando se realizó el relleno del muelle pesquero, los baños de La Marina se trasladaron a la

\footnotetext{
${ }^{3}$ ROSSELlÓ VERGER, V. M., «Aspectos físicos», ap. en Geografia de la provincia de Alicante, Alicante, Diputación Provincial, 1978, págs. 29-31.
} 
playa del Cura, hoy uno de los lugares más saturados y congestionados y que, sin embargo, en aquellos años fue necesario promocionar con un servicio gratuito de autobuses.

En los expedientes de solicitud de montaje de balnearios siempre se hacía constar: «(...) como se viene haciendo desde tiempo inmemorial», lo que parece confirmar que los balnearios tienen tanta antigüedad como la misma Torrevieja, juicio que confirma un autor de finales del siglo XVIII ${ }^{4}$.

La aparición y proliferación de los balnearios se relaciona con las prescripciones médicas y los novenarios desde el setecientos; en estos establecimientos se preparaban baños con algas marinas a la temperatura recomendada, de acuerdo con unas tablas donde se especificaba el tratamiento concreto que requerían las distintas enfermedades reumáticas o circulatorias para su curación $^{5}$. Las condiciones higiénicas eran una cuestión esencial en los balnearios, al igual que en los hoteles, y muy especialmente en las tres primeras décadas del siglo actual (probablemente ello venía motivado por la cantidad de enfermedades contagiosas que afectaban a la población), razón por la que todos los establecimientos, cuando insertaban propaganda en los periódicos, insistían de una manera especial en las excelentes condiciones higiénicas que se ofrecían.

La clientela permanente de los balnearios la formaba la clase alta, si bien los días festivos se desataba una auténtica avalancha de gente de Murcia y del Bajo Segura, que constituían la corriente itinerante del veraneo y llenaban estos establecimientos en días como el de San Jaime, llegados en trenes especiales y en carros, y que abandonaban el pueblo durante la noche.

4) Los medios de transporte.- Conviene en principio resaltar el papel fundamental que el ferrocarril ha tenido para el desarrollo del turismo desde que a fines del siglo XIX entró en funcionamiento la vía Albatera-Torrevieja, cuya construcción no sólo obedece a los imperativos de la producción salinera sino que pone de manifiesto la idea de potenciar el núcleo turístico con un medio [120] de transporte cómodo y económico, que permitía un fácil acceso desde los núcleos emisores (Murcia, Orihuela, Callosa del Segura, etc...). Al mismo tiempo, los hoteles más prestigiosos de la villa contaban con un servicio de carruajes para el transporte de viajeros desde la estación.

A partir de la Guerra Civil el ferrocarril se desarrolla también extraordinariamente como medio de transporte para la avalancha de gente del Bajo Segura que viene a Torrevieja los fines de semana y que son el preludio del turismo de masas de los años sesenta, aunque con carácter no residente 6 . Pero ante la competencia del transporte colectivo por carretera, más cómodo y económico, en 1970 se decidió suprimir la estación de viajeros de Torrevieja.

El papel que en su día representó el ferrocarril es asumido por la carretera, a lo que ha contribuido muy eficazmente la mejora de la red viaria (N-332, C-3321, A-332) y el ágil funcionamiento de las líneas de autobuses que enlazan con la capital provincial, Bajo Segura y Murcia, reforzada esta última durante los meses estivales con autobuses de servicio discrecional y nuevas líneas turísticas, como la que comunica Torrevieja con el Mar Menor.

La proximidad del aeropuerto de El Altet contribuye de un modo decisivo a mejorar la oferta turística al disponerse de un medio de transporte de gran importancia para el turismo internacional.

${ }^{4}$ MONTESINOS, Compendio Histórico Oriolano, (manuscrito), T. XII.

\footnotetext{
${ }^{5}$ Agradezco la información facilitada por D. Antonio Albacete Antón, antiguo propietario de los baños de La Marina.
}

${ }^{6}$ Según datos facilitados por don Pedro Jorque, antiguo factor de la estación de Torrevieja, en torno a 1945 llegaban unos 600-700 viajeros en el fin de semana, durante los meses de verano, cifra que se fue incrementando hasta el período 1966-69 en el que se alcanza un número de 1.200 y hasta 1.500 viajeros, para lo que era necesario habilitar trenes especiales desde Murcia a Torrevieja. 


\section{TURISMO TRADICIONAL: CARACTERÍSTICAS Y FORMAS DE OCUPACIÓN DEL ESPACIO}

Torrevieja aparece como núcleo de veraneo en la primera mitad del siglo XIX, si bien hay noticias de su función turística en las postrimerías del setecientos (Montesinos). Ya se han apuntado varios factores que determinan la aparición y expansión posterior de la estación turística, pero conviene resaltar que hay una importante y clara razón económica que coadyuvó a la potenciación progresiva de la función turística. Se trata de la necesidad de buscar otras fuentes de ingresos por parte de la población residente en este municipio, cuya actividad económica se centraba en torno a la mar y a la explotación salinera. En efecto, así como Arroyo ${ }^{7}$ señala en un estudio sobre Tavernes de Valldigna que la riqueza de las tierras del litoral valenciano excluía la necesidad de buscar fuentes de ingresos alternativas, no ocurre así en este sector litoral, sometido a crisis periódicas con claro reflejo en la evolución demográfica.

No conviene sin embargo exagerar la importancia del veraneo tradicional, [121] ya que no se produce una modificación trascendental de la estructura urbana y demográfica del municipio. En sus inicios se trata de un turismo de balneario, a la vez que selectivo y a veces aristrocrático. La colonia veraniega la componen grandes terratenientes, propietarios y profesiones liberales del Bajo Segura y Murcia y, en menor medida, de Madrid.

A la corriente de veraneo selectivo se une, desde una postura opuesta, el turismo de carácter eventual de las clases rurales del Bajo Segura, cuyo origen hay que buscarlo en las gentes de la huerta y del campo que salían en carros «a pasar el día», tal y como se constaba en otros sectores litorales ${ }^{8}$ y que, a raíz de la construcción del ferrocarril, se desbordan en los días festivos de julio y agosto sobre Torrevieja.

Hacia 1915 la favorable situación económica local determinada por el auge de la marina mercante se acompaña de una proyección exterior de la imagen turística del municipio; prueba de ello es la edición de periódicos y revistas (El Pueblo) que llegan hasta Madrid y en los cuales se ofrece a los lectores la posibilidad de un «veraneo gratis» en Torrevieja. En estos periódicos se refleja el tipo de turismo selectivo que se desarrollaba y que a la vez se quería atraer, con marcado hincapié en el bienestar y confort de los balnearios y en la higiene de los hoteles 9 .

También con la idea de potenciar el turismo se celebraban las Ferias Oficiales de Verano y, a partir de 1955, se inicia la celebración del Certamen Nacional de Habaneras y Polifonía, expresión de los lazos creados con la ciudad de La Habana por la actividad marinera, pero unido a iniciativas de ciertas personalidades murcianas y madrileñas que pasan su veraneo en Torrevieja (no extraña pues que el diario $\mathrm{ABC}$ dedicara su primera plana a la inauguración del Certamen).

Por lo que se refiere a la ocupación del espacio, fue en torno al decenio de 1910 cuando se construyen las primeras residencias veraniegas, denominadas hotelitos, en el frente de mar, desde Las Rocas hacia la playa del Cura a iniciativa de las clases pudientes de Madrid, Murcia, Orihuela y resto del Bajo Segura. Ya en la década de 1920 se levantó el grupo de chalés conocido como Los Palomares, en la playa del Cura, y, algo antes, el barrio de Antonio Vera «El Pequero», que constituyen el sector de ocupación más antiguo del turismo residencial.

Pero la impronta espacial del turismo tradicional, además de las residencias levantadas

${ }^{7}$ ARROYO ILERA, F.: «La playa de Tabernes de Valldigna (Valencia)», Estudios Geográficos, N. ${ }^{\circ}$ 159, 1979, pág. 75.

${ }^{8}$ LÓPEZ GÓMEZ, A.: «El veraneo tradicional en las costas valencianas. Barraques y casetes de la mar en la huerta de Gandía», Cuadernos de Geografia, N. ${ }^{\circ} 22$, Valencia, 1978, págs. 10-11.

${ }^{9}$ El Pueblo, N. ${ }^{\circ} 88,1915$. 
en el frente costero, adopta formas peculiares y tiene a la vez en gran parte un carácter estrictamente temporal. Se [122] trata de los balnearios y de las casetas de mar que se montan en los últimos días de junio o principios de julio y se vuelven a desmontar en los últimos días de septiembre. En principio, pues, conviene insistir en el carácter temporal de las construcciones, ya que una vez acabada la temporada de baños, no queda ningún elemento de aquéllas en las playas, condición ésta que se hace constar en las solicitudes de casetas: «... (las casetas deberán) ser desmontables, sin material sólido de ninguna clase, sólo valedera para la temporada de baños, quedando el solicitante obligado a desmontarla y retirarla de la playa antes del día $1^{\circ}$ del próximo mes de octubre $(. .).\rangle^{10}$.

El análisis de los expedientes de solicitud de casetas dirigidos al Ayuntamiento en el período 1927-32 pone de relieve su pertenencia a una clase social elevada: los solicitantes son médicos, abogados o propietarios que acuden a Torrevieja. Se añaden otras de propietarios locales que los arriendan a los foráneos.

Desde 1940 se opera un cambio sustancial en este tipo de construcciones, con un aumento considerable de su número (unas 300 en la playa del Cura y, sobre todo, en El Acequión) debido a la proliferación de las denominadas casetas-vivienda, construidas por gentes de la huerta de bajo nivel de renta. Estas casetas desaparecen junto con los balnearios en los años sesenta y fue este hecho el que motivó la construcción de los primeros chalés en el sector de la carretera a Cartagena y La Casa Negra, donde los precios del suelo eran más bajos.

En definitiva, interesa resaltar del turismo tradicional que su impronta espacial se mostraba integrada y en armonía con el paisaje litoral, sobre todo por el carácter temporal de los establecimientos de baños y casetas de mar, hecho que contrasta con las nuevas formas de ocupación permanente y disposición anárquica que crea el turismo residencial y masificado. En este sentido, cabe también resaltar que en los sectores de ocupación turística más antigua las residencias rodeadas de jardines han sido sustituidas por enormes torres de apartamentos que forman una muralla de hormigón en el frente costero de las playas.

Desde el punto de vista económico el turismo tradicional no daba empleo permanente a la población, pero sí constituía un complemento indispensable para la economía tradicional (pesca y explotación salinera), a la vez que beneficiaba a una mayor parte de la población, en función del alquiler de viviendas que solía practicarse. Este hecho merece ser destacado, ya que con el turismo de masas, si bien se produce un mayor aporte de capitales, los beneficios se escapan en buen parte de las manos de la población autóctona.

Asimismo y desde el punto de vista social, el carácter minoritario del veraneo tradicional y la asiduidad de los veraneantes se traducían en una relación [123] más estrecha con la población residente, que tampoco suponía una alteración sustancial de los modos de vida.

\section{EL TURISMO DE MASAS: CARACTERÍSTICAS Y REPERCUSIONES}

Como señala J. Cals ${ }^{11}$, el turismo actual no es una simple transformación cuantitativa de aquel turismo de balneario, sino el reflejo de dos situaciones estructurales distintas. El turismo moderno nace con la civilización industrial y el litoral mediterráneo se convierte en un espacio de ocio para la Europa industrializada. Es a partir de 1965 aproximadamente cuando el turismo de masas irrumpe en Torrevieja, aunque con poca importancia hasta los años setenta. El espacio deja de ser factor de producción para convertirse en objeto de consumo; cambian las prioridades

\footnotetext{
${ }^{10}$ Archivo Municipal de Torrevieja, Memoria explicativa de una caseta de madera para baños de mar, julio de 1927, sin foliar.

${ }^{11}$ CALS, J.: Turismo y política turística en España: una aproximación. Barcelona, Ariel, 1974, pág. 34.
} 
de usos del suelo y de los demás recursos naturales, a la vez que la línea litoral se va congestionando ante la avalancha y se produce una transformación radical no sólo del espacio sino también de los modos de vida, hábitos, etc... El turismo se enseñorea del espacio y orienta los demás sectores productivos a sus exigencias, con una masiva terciarización de la población activa pero, sobre todo, un engrosamiento espectacular y artificial del subsector construcción y de otros subsectores dependientes de él, todo ello en función del auge urbanizador. La morfología del núcleo cambia radicalmente, a la vez que se expande a lo largo del eje costero. La imagen del turismo tradicional se borra definitivamente con la desaparición de las casetas y balnearios y la elevación de grandes bloques de apartamentos, algunos de más de diez plantas, en la línea costera, donde antes aparecían las residencias veraniegas del turismo selectivo.

En un período de aproximadamente 15 años la función agrícola de las tierras del litoral se ve suplantada por la función recreativa y del ocio, lo que determina la aparición de un nuevo paisaje, caracterizado por la desaparición de cultivos y masas vegetales, remodelación del hábitat en base a la generalización del poblamiento diseminado no ligado a la actividad productiva, modificación de la red caminera y de la articulación del espacio. En definitiva, un cambio morfológico y estructural espectacular como reflejo de la implantación de la actividad turística.

\section{Mercado del suelo y plusvalías territoriales}

La demanda de espacio en el litoral, debida al desarrollo del turismo residencial, provoca un alza espectacular del valor del suelo. A través del análisis de los libros del Registro de la Propiedad se ha constatado que las primeras compras de terrenos fuera del núcleo de la población empiezan a ser importantes a fines de los años cincuenta. En efecto, es en aquellas fechas cuando el suelo comienza a revalorizarse de una manera extraordinaria en relación a [124] la importancia creciente de la función turística. Secanos de escaso o nulo aprovechamiento económico, que integraban las antiguas haciendas del litoral, entre La Mata y El Torrejón, experimentaban enormes plusvalías que, como señalan Bastié y Dezert ${ }^{12}$ originan la especulación, puesto que en no pocos casos las parcelas son adquiridas en espera de que su valor aumente y no para construir. Los compradores son gentes de Orihuela, Murcia, Madrid e incluso de la propia Torrevieja, que invierten el dinero ante las expectativas de obtener un amplio beneficio en pocos años. En un primer momento son parcelados los terrenos de la línea costera, el frente de mar, a lo largo de la carretera a El Torrejón; el precio de la tierra aumenta de una manera extraordinaria, de modo que las parcelas del sector de la playa de Los Locos que en 1950 se vendían a $15-20$ pts. $/ \mathrm{m}^{2}$, en 1960 costaban a razón de $200 \mathrm{pts} . / \mathrm{m}^{2}$. El tamaño de los solares solía oscilar en torno a los 200 $\mathrm{m}^{2}$, si bien hubo casos de compras de más de $1.000 \mathrm{~m}^{2}$, aunque muy esporádicamente, puesto que no hay que olvidar que los mismos propietarios de las fincas revalorizadas, alertados por las posibilidades del negocio, deciden parcelar ellos mismos y no vender el conjunto.

Es posible discernir al menos dos corrientes de actuación en el negocio de compra de terrenos en aquellas fechas:

-propietarios, agricultores y profesiones liberales de los pueblos próximos o incluso de Madrid, que adquieren pequeñas parcelas como forma de invertir en un negocio sin riesgos y que ofrecía un alto beneficio o bien para la construcción de segundas residencias.

-grandes inversores nacionales o extranjeros, especuladores en muchos casos, que invierten importantes cantidades de dinero en la compra de terreno rústico para realizar parcelaciones, a la vez que esperan la revalorización de la tierra.

Por lo que se refiere a las compras de terrenos por extranjeros, éstas empiezan a ser importantes a mediados de la década de 1960, en relación con el desarrollo espectacular del

${ }^{12}$ BASTIÉ, J., y DEZERT, B., L 'espace urbain, París, Masson, 1980, pág. 95. 
turismo de masas en el litoral mediterráneo y al consiguiente proceso de urbanización. En efecto, la primera gran penetración de capital extranjero se produce en 1966. Se trata de la venta de parte $\left(15.239 \mathrm{~m}^{2}\right)$ de una finca de secano realizada por una familia de terratenientes locales a una comunidad de $50 \operatorname{suecos}^{13}$ para la construcción de la colonia denominada Lomas del Mar. Al mismo tiempo, un industrial también de origen sueco adquirió 12 ha 15 a 27 c., de las que se han ido produciendo segregaciones hasta fechas recientes, de entre las cuales destaca la que tuvo lugar en $1967\left(14.799 \mathrm{~m}^{2}\right)^{14}$, cuyo conjunto pasó a manos de otra comunidad de 47 suecos, con $150 \mathrm{~m}^{2}$ per capita, para construir el grupo II Lomas del Mar: en este caso la especulación se producía entre inversores de la misma nacionalidad. Las [125] actuaciones en el mercado inmobiliario por parte de comunidades de extranjeros, suecos por lo general, se suceden en la segunda mitad de los años sesenta y es así como también en 1967 fueron vendidos $6.250 \mathrm{~m}^{2}$ a otro grupo de extranjeros ${ }^{15}$. Estas comunidades de nórdicos actuaban a través de un representante en España y adquirieron terrenos en los lugares de mayor atractivo natural, entre Cabo Cervera y las dunas de La Mata, donde llegaron a constituir una verdadera colonia de cuya importancia da cuenta la existencia de un Viceconsulado de Suecia en Torrevieja, si bien ello también obedece a los imperativos del tráfico marítimo (embarque de sal).

Una nueva e importante entrada de capital extranjero, por sus efectos económicos y paisajísticos, se inicia en $1973^{16}$, vinculada a un comerciante alemán como representante de la empresa Testa Euro-Bau, S.A., la cual, a través de la figura del testaferro, adquirió terrenos en la franja costera comprendida entre la pedanía de La Mata y el cordón dunar que atraviesa la carretera de la costa, donde se levantaron grandes torres de apartamentos que serían vendidos a la clase trabajadora alemana, no sin grandes estafas. Un año después otra empresa extranjera que ya venía actuando en Benidorm, R.O. International Spain, S.A., adquirió 2 ha 42 a $50 \mathrm{c}$ en La Mata.

A grandes rasgos, la actuación de los inversores extranjeros se ha caracterizado por la adquisición de grandes extensiones en lugares de un claro atractivo natural, con marcada preferencia por el frente de mar. Sin embargo, hay que resaltar la diferente actuación, en cuanto a tipos de ocupación del suelo, de las comunidades de nórdicos, con un marcado predominio de la vivienda unifamiliar aislada y, frente a ello, el capital alemán, orientado a la construcción de grandes moles de apartamentos con una clara finalidad especulativa.

Fue precisamente la especulación la que hizo entrar en el negocio inmobiliario, en el decenio de 1970, a grandes propietarios agrarios, que luego venden los terrenos adquiridos en el litoral a promotoras madrileñas; es así como en 1975 un comerciante de Murcia adquiere 80 ha ${ }^{17}$ que irá segregando posteriormente y en 1977 un industrial de Callosa del Segura ${ }^{18}$ se introduce en el mercado de suelo de Torrevieja. Al mismo tiempo también siguen apareciendo algunos industriales de otras provincias, cuya actuación en la zona se viene constatando desde 1965, con la compra de una hacienda del litoral realizada por un industrial navarro. Las tierras vendidas suelen ser espacios de anterior aprovechamiento agrario, plantadas de viña en el sector

\footnotetext{
${ }^{13}$ Registro de la Propiedad de Orihuela, T. 414,30 de Torrevieja.

${ }^{14}$ Registro de la Propiedad de Orihuela, T. 453,33 de Torrevieja.

${ }^{15}$ Registro de la Propiedad de Orihuela, T. 460,34 de Torrevieja.

${ }^{16}$ Registro de la Propiedad de Orihuela, T. 611,47 de Torrevieja.

${ }^{17}$ Registro de la Propiedad de Orihuela, T. 642,50 de Torrevieja.

${ }^{18}$ Registro de la Propiedad de Orihuela, T. 692,58 de Torrevieja.
} 
de La Mata y destinadas al cultivo del cereal en El Torrejón. Pero la especulación en la venta de terrenos también afectó a algunos espacios naturales, que deberían haber sido protegidos como fue el caso de las dunas entre Cabo Cervera y La Mata, amenazadas hoy con desaparecer en su práctica totalidad. [126]

Los últimos años del decenio de 1960 y hasta 1974 se caracterizan por un fuerte auge de la actividad urbanizadora. Es un período en el que se construyen conjuntos residenciales mediante la aprobación de Planes Parciales de Urbanización en anterior suelo rústico, a la vez que la demanda de apartamentos y chalés contribuye a aumentar cada vez más el valor del suelo con posibilidades de urbanización. En el frente de mar se empieza a acusar una selección de compradores, que dará origen a una zonificación social, mientras el alto coste del suelo induce a los promotores, madrileños y murcianos esencialmente, a construir en altura y concentrar un elevado índice de viviendas por $\mathrm{m}^{2}$ de terreno, todo lo cual motiva una transformación radical del paisaje en la línea costera, a la vez que cambia la morfología del núcleo urbano.

Con la idea de profundizar en el estudio de las tendencias en el mercado del suelo, se ha realizado un análisis de los Expedientes de Plusvalía de varios años, de entre los cuales se extrae como significativo $1977 \mathrm{y}$, más concretamente, de aquellos expedientes que gravan solares de más de mil metros cuadrados. Un 70\% son compras de terrenos entre 1.000 y $2.000 \mathrm{~m}^{2}$, cuyos propietarios proceden de núcleos del Bajo Segura (esencialmente constructores de Bigastro) o bien se trata de empresas dedicadas a la construcción de grandes edificios. Otro $25 \%$ afecta a parcelas entre 2.000 y $10.000 \mathrm{~m}^{2}$ cuyos compradores son dos suecos, una empresa constructora y dos particulares. Sólo se constata un caso de un solar de más de $20.000 \mathrm{~m}^{2}$, adquirido por un belga dedicado al negocio inmobiliario.

Desde 1977 los inversores ya no se orientan, salvo muy pocos casos, a la compra de solares que dejan sin construir en espera de que se revaloricen, sino que se impone una nueva estrategia determinada por el boom del turismo de masas entre 1977 y el momento actual, que supone el inicio de un nuevo período caracterizado por la construcción de grandes edificios a lo largo de la costa, cuyos promotores compran solares y los edifican inmediatamente.

Otro sector del municipio se revaloriza extraordinariamente en esos años, se trata de la playa del Acequión, hasta el paraje denominado La Casa Negra, a ambos lados de la carretera a Cartagena: los terrenos que en 1960 se pagaban a 100 y a 200 pts. $/ \mathrm{m}^{2}$, en 1975 se compraban a 1.000 pts. $/ \mathrm{m}^{2}$, pero entre 1979 y 1983 el precio aumenta de una manera espectacular: en 1980 se pagaron por un solar de $3.000 \mathrm{~m}^{2}$, en primera línea, 30 millones de pesetas.

El mercado del suelo ha vuelto a moverse en el presente año debido a algunas operaciones importantes de ventas de solares a compañías madrileñas o del Bajo Segura, para la elevación de bloques de apartamentos. La causa esencial del estancamiento en los últimos años es la inflación y el alto porcentaje de interés fijado en los créditos que conceden las instituciones financieras privadas.

Resulta significativo que en el sector de la playa del Cura, en primera línea del mar, donde se encontraban las residencias de la clase acomodada hasta hace algunos años, se hayan llegado a pagar 40 millones por $2.000 \mathrm{~m}^{2}$ de terreno, si bien el alza del valor del suelo y su escasez determinan que el [127] espacio se aproveche al máximo, con la construcción en altura y mayor grado de hacinamiento de los residentes. La transformación del paisaje se acompaña de una zonificación diferente, determinada por el precio del suelo y la calidad y tipología de las construcciones: los mejores edificios aparecen en el frente de mar.

De las tres formas de urbanización del litoral señaladas por Michaud ${ }^{19}$, se ha llegado ya a la fase del muro de hormigón, con una radical transformación de las zonas afectadas. Asimismo, y como consecuencia de la saturación de la costa y del alto coste del suelo, la

${ }^{19}$ MICHAUD, J. L., Ob. cit., pág. 181. 
especulación penetra hacia las tierras del interior; las urbanizaciones se extienden y enseñorean del espacio que bordea la laguna de las salinas, a expensas de las tierras de cultivo o de los saladares, sobre todo en los parajes de La Punta de La Víbora, El Chaparral y Los Balcones. Son suelos calificados como rústicos que mediante la aprobación de Planes Parciales y Planes Especiales de Transformación, se convierten en superficies edificables, con un evidente deterioro paisajístico y fuertes tensiones espaciales.

\section{La ocupación del espacio}

El proceso de ocupación del suelo se ha estudiado a partir del análisis de las licencias de obras, completado con la encuesta y el trabajo de campo. Con esta finalidad se han delimitado unas áreas que comprenden en suma todo el término municipal, pero se ha excluido el casco urbano propiamente dicho, ya que el predominio de población residente desvirtuaría el análisis del crecimiento inducido por el turismo. Hay sin embargo algunas calles del núcleo que se han considerado en el estudio, dado que sus edificaciones tienen una función esencialmente turística y pasan 10 meses del año cerradas, caso éste de todo el sector de la playa del Cura en el cual, a pesar de que mantiene una indudable unidad con el núcleo urbano, las edificaciones son residencias secundarias y chalés de alquiler en más del $90 \%$ de los casos.

Desde mediados de la década de 1960 es posible discernir tres etapas, en atención al tipo de edificación que se construye preferentemente en cada una de ellas y a la estrategia de los promotores:

1) Entre 1965 y hasta 1974 se observa un predominio de los conjuntos de urbanizaciones promovidas por sociedades madrileñas, murcianas o extranjeras cuya localización preferente es el frente de mar, si bien algunas buscan lugares de topografía elevada, algo más apartados. Al mismo tiempo se da un auge en la construcción de chalés y residencias secundarias en base a iniciativas particulares sobre parcelas de antiguas fincas litorales.

2) Desde 1975 y hasta 1979 es la época de desarrollo de los bloques de apartamentos en la que algunos sectores del municipio se ven más afectados y [128] transformados, caso de la playa del Acequión y la del Cura y la pedanía de Torrelamata. Los promotores suelen ser del Bajo Segura, sobre todo de Bigastro.

3) Entre 1979 y el momento actual se constata un nuevo impulso de las urbanizaciones, situadas ahora más al interior, en torno a la laguna, por la falta de suelo en el litoral y su elevado precio, y con una diferente tipología de las construcciones, ya que predominan los bungalows, de baja calidad en la construcción y extraordinariamente aglomerados (La Torreta). Aparecen también conjuntos de bloques de apartamentos, como continuación de las iniciativas de la etapa anterior, si bien ahora también intervienen empresas de Madrid. Deterioro paisajístico y hacinamiento son los rasgos más sobresalientes de esta etapa. 
CUADRO I

\begin{tabular}{|c|c|c|c|c|c|c|c|c|}
\hline \multicolumn{9}{|c|}{ Origen geográfico de los promotores } \\
\hline \multirow[t]{2}{*}{ LUGARES } & \multicolumn{2}{|c|}{1966} & \multicolumn{2}{|c|}{1974} & \multicolumn{2}{|c|}{1977} & \multicolumn{2}{|c|}{1982} \\
\hline & $N .{ }^{\circ}$ & $\%$ & $N e^{e}$ & $\%$ & $N:^{\circ}$ & $\%$ & $N .^{\circ}$ & $\%$ \\
\hline Torrevieja * & 19 & $28^{\prime} 3$ & 29 & $47 ' 5$ & 84 & $54^{\prime} 1$ & 82 & $68 ' 3$ \\
\hline Orihuela & 12 & $17 ' 9$ & 8 & $13{ }^{\prime} 1$ & 30 & $19 \cdot 3$ & 8 & 6'6 \\
\hline Callosa del Segura & 8 & 11,9 & 4. & $6 \cdot 5$ & 7 & $4 ' 5$ & 3 & 2,5 \\
\hline Bigastro & 2 & $2 \% 9$ & 4 & 6.5 & 6 & 38 & 1 & $0^{\circ} 8$ \\
\hline Resto del Bajo Segura & 9 & $13 \% 4$ & 3 & 49 & 7 & $4^{\prime} 5$ & 3 & $2: 5$ \\
\hline Murcia & 6 & 899 & 3 & 4 & 11 & $7 \times 0$ & 2 & $1 ' 6$ \\
\hline Madrid & 4 & 5,9 & 1 & $1 ' 6$ & 1 & 0,6 & 3 & $2 ' 5$ \\
\hline Otras provincias & 7 & $10^{\prime} 4$ & 9 & $14 ' 7$ & 9 & $5>8$ & 18 & $15^{\prime} 0$ \\
\hline Totales & 67 & & 61 & & 155 & & 120 & \\
\hline
\end{tabular}

Fuente: Expedientes de licencias de obras. Ayuntamiento de Torrevieja.

*Hay que tener muy en cuenta el hecho de que en bastantes ocasiones se consigna ciudad en casos cuya residencia es accidental. Es por ello bastante frecuente que promotores extranjeros aparezcan como residentes en Torrevieja y, sobre todo, en el caso de la urbanización Los Balcones, cuyos promotores siempre aparecen como residentes en la misma.

Los inicios del auge de la construcción se encuentran en la iniciativa de las clases medias de Orihuela, Bajo Segura y Murcia en el sector de la playa del Cura y, con menor importancia, en el Torrejón, Los Locos y carretera de Cartagena. Un 40\% de las licencias de obras concedidas en 1966 afectan a construcciones en la playa del Cura, un 8,3\% al Torrejón y un 14\% a la carretera de Cartagena. De esta misma fecha data el primer Plan Parcial de Urbanización, promovido por la Caja de Ahorros de Nuestra Señora de Monserrate [129], en terrenos de El Torrejón, se trata de la urbanización Villa Sol, que inicia el proceso de colonización nodular del espacio costero, donde hasta el momento sólo aparecían algunas construcciones puntuales. Entre 1967 y 1968 son aprobados los Planes Parciales de Cabo Cervera, Lomas del Mar, Molino Blanco, Punta Prima, La Veleta y Los Balcones, si bien debe tenerse en cuenta que la aprobación de los Planes Parciales no se traduce necesariamente en un proceso de construcción inmediato. Estas urbanizaciones provocan un cambio en las prioridades del uso del suelo y de otros recursos naturales escasos como el agua.

A fines de los años sesenta continúa la tendencia de auge en la construcción pero entre 1970 y 1974 el aumento es espectacular: una sola urbanización, Los Balcones, acapara el 47,2\% de las licencias, si bien no hay que olvidar que cada propietario solicita particularmente el permiso para construir, a diferencia de los grandes bloques, cuyos promotores solicitan una licencia para todo el conjunto. Este hecho es importante tenerlo en cuenta en el sentido de que el descenso del número de licencias en un sector no obedece a una disminución de la actividad constructora sino a la diferente estrategia de los promotores que venden el apartamento construido, 


\begin{tabular}{|c|c|c|c|c|c|c|}
\hline \multicolumn{7}{|c|}{$\begin{array}{c}\text { CUADRO } 2 \\
\text { Evolución de las licencias de obras* }\end{array}$} \\
\hline Añus & $\begin{array}{l}\mathrm{N} *^{\circ} \text { de } \\
\text { licencias }\end{array}$ & $\begin{array}{l}\text { Fisulre total } \\
\text { muntcipal }\end{array}$ & $\begin{array}{c}\text { de } 1 \\
\text { virienda }\end{array}$ & $\begin{array}{c}\text { entre } 2 \\
y 5\end{array}$ & $\begin{array}{l}6 \mathrm{a} \\
10\end{array}$ & $\begin{array}{l}\text { más de } \\
10\end{array}$ \\
\hline 1965 & 48 & $34 ' 5$ & 28 & 10 & 2 & 8 \\
\hline 1966 & 63 & $33 \times 3$ & 33 & 19 & 3 & $\varepsilon$ \\
\hline 1967 & 72 & $40^{\circ} 9$ & 31 & 23 & 11 & 7 \\
\hline 1968 & 40 & $22^{\prime} 0$ & 14 & 16 & 7 & 3 \\
\hline 1969 & 37 & $29^{\prime} 8$ & 23 & 10 & 2 & 2 \\
\hline 1970 & 41 & $32 ' 8$ & 22 & 19 & - & - \\
\hline 1971 & 95 & $56 ' 5$ & 58 & 16 & 13 & 3 \\
\hline 1972 & 58 & $38^{\prime} 9$ & 22 & 14 & 8 & 14 \\
\hline 1973 & 85 & 45,4 & 30 & 25 & 6 & 19 \\
\hline 1974 & 85 & $47^{\circ} 4$ & 42 & 26 & 5 & 16 \\
\hline 1975 & 167 & $63 \cdot 4$ & 75 & 66 & 3 & 17 \\
\hline 1976 & 141 & $52 ' 8$ & 98 & 23 & 3 & 17 \\
\hline 1977 & 206 & $62^{\prime} 0$ & 113 & 48 & 7 & 38 \\
\hline 1978 & 252 & 70.5 & 147 & 73 & 11 & 21 \\
\hline 1979 & 237 & $67 \%$ & 111 & 77 & 19 & 30 \\
\hline 1980 & 200 & $69^{\prime} 2$ & 114 & 48 & 14 & 24 \\
\hline 1981 & 143 & $66^{\prime} 2$ & 90 & 21 & 7 & 25 \\
\hline 1982 & 156 & $79^{\prime} 5$ & 99 & 18 & 15 & 27 \\
\hline
\end{tabular}

Fuente: Expedientes de licencias de obras. Ayuntamiento de Torrevieja. *Sólo se consideran las licencias para edificios con clara finalidad turística (vid. pág. 127).

[130]

en contraste con el propietario de una parcela que construye por propia iniciativa su chalé. Son aprobados en estos años los Planes Parciales de Los Ángeles, La Torreta y El Chaparral, estas dos últimas alejadas de la costa, en tierras de labor y saladar cerca de la laguna salada.

En los momentos de mayor actividad en la construcción conviene establecer una diferenciación básica entre, por un lado, los promotores procedentes del Bajo Segura, que pueden ser particulares que solicitan la licencia para construir su propia vivienda o bien maestros de obras que construyen bloques, en muchos casos subvencionados, y que se sirven de mano de obra de sus poblaciones de origen; y de otro lado, las sociedades, madrileñas por lo general, aunque con participación extranjera, y una ilicitana (MASA) que transforman grandes extensiones de suelo rústico en urbanizable y se dedican a la construcción de bungalows en serie.

En 1975 se aprueba el Plan Parcial Aguas Nuevas, con capital belga, que da origen a la colonización con chalés y bungalows de un sector de lomas en el llamado alto de La Mata, junto a la carretera a Alicante. Hasta 1979 dos urbanizaciones crecen extraordinariamente, Los Balcones y La Torreta (52\% de las licencias de un total de 206 en 1979) pero la mayor actividad constructora se centra en el sector de la playa del Acequión y del Cura, con la elevación de torres de apartamentos. A partir de 1980 se constata un descenso importante en el número de licencias que obedece, por una parte, al auge de urbanizaciones de bungalows en las que el promotor solicita una licencia para construir un conjunto de viviendas, a veces más de 100 , frente al sistema anterior de venta de parcelas en las que una licencia equivalía a una vivienda. Por otra parte, la crisis económica ha influido negativamente en el sector de la construcción: el estancamiento de la demanda y el exceso de oferta se han traducido en una ralentización del proceso de construcción.

Tipología de las edificaciones

De un total de 9.005 edificios censados en el término en 1980 , el $82,6 \%$ son de una 
vivienda. Este predominio de los edificios unifamiliares viene determinado por la tipología de las edificaciones en el casco de la ciudad, caracterizado por la abundancia de las viviendas unifamiliares de una planta. Por otra parte, la proliferación de edificios unifamiliares también se justifica en buena parte por la gran cantidad de bungalows y chalés individuales construidos en los últimos cinco años en los alrededores de la laguna y a lo largo de la línea costera. En efecto, si se desglosa el análisis de las edificaciones entre el núcleo y el diseminado, resulta que en el núcleo, de un total de 5.428 edificios, el 73,7\% son de una vivienda, mientras que en el diseminado, de un total de 3.577 edificios, 3.442 (96,2\%) son de una vivienda. Estas cifras pueden también darnos idea de la importancia de las urbanizaciones que se han realizado en el término municipal y de la tipología de las edificaciones que en éstas predomina, ya que el 39,7\% de los edificios del municipio pertenece a zonas de reciente urbanización (Planes Parciales). [131]

Otro dato de interés es el estudio de los edificios según el número de plantas. En este sentido, del total referido de 9.005 edificios del término municipal hay un evidente predominio de los de una planta, $73,2 \%$, en relación, como ya se ha señalado, al importante número de edificios de una vivienda, en su doble vertiente, por un lado vivienda unifamiliar tradicional de una planta dentro del núcleo urbano y, de otro lado, pequeños bungalows unifamiliares, también de una planta, en el diseminado. Resulta interesante constatar que los grandes bloques con más de 10 plantas sólo suponen un $0,3 \%$ del total, lo que contrasta con otros núcleos turísticos, como puede ser el mismo Benidorm, donde estos edificios representan el 73,6\% del total, mientras los de una planta sólo suponen el 33,1\%. Ello es debido a la forma en que se desarrolla en estos dos núcleos la expansión del turismo residencial, lo que se refleja en la tipología de los inmuebles; al mismo tiempo, influye decisivamente el precio del suelo urbanizable y las disponibilidades del mismo.

El Censo de viviendas de 1980 arroja la cifra de 19.517 viviendas familiares en el término, de las cuales sólo 3.529 son de ocupación principal (18\%), mientras que el 76,8\% de aquéllas son de ocupación secundaria y el 4,6\% aparecen como desocupadas. Estas cifras dan una idea de la importancia del turismo residencial en el municipio, con lo que queda claro el hecho de la ocupación temporal de un buen número de viviendas, la mayor parte de las cuales permanecen cerradas 10 meses al año. Este análisis cobra mayor significación si se realiza por distritos y secciones padronales. Es así como de los tres distritos en los que se divide el municipio, el tercero cuenta con 9.144 viviendas (46,8\% del total), de las que 6.072 se han censado como vacías. El distrito $2^{\circ}$, cuyas dos secciones son mixtas, cuenta con un $54,5 \%$ de viviendas vacías, mientras el porcentaje de viviendas no habitadas en el distrito $1^{\circ}$ es del $45,4 \%$.

Se constata pues que las residencias de ocupación secundaria aparecen repartidas por todo el municipio, pero es evidente una concentración más espectacular de éstas en el distrito $3^{\circ}$, correspondiente a la zona de El Torrejón, La Loma y Los Gases, es decir, el área más afectada por la expansión del turismo residencial.

De este modo, el turismo se presenta como el factor que ha provocado la urbanización de Torrevieja y la transformación radical del paisaje, con la aparición de un espacio urbano en lo que era espacio rural o incluso natural. La fisonomía de un pequeño núcleo que en 1958 se extendía desde el canal del Acequión a la actual Plaza de Oriente, cambia radicalmente con la expansión a lo largo de la costa y origina una ciudad lineal, a la que posteriormente se añade una colonización nodular en los contornos de la laguna. Al mismo tiempo, se transforma la estructura urbana y la tipología de los inmuebles, con un marcado predominio de la construcción en altura en el núcleo antiguo y en el frente de mar. [132]

Avance de Planeamiento del P. G. O. U.: su influencia en la organización del espacio 
El crecimiento urbano, entre 1974 y el momento actual, ha estado regulado por el P.G.O.U. del término municipal de Torrevieja, de 1974, completado en determinados casos con la aplicación de las Normas de Ordenación Complementarias y Subsidiarias de los municipios de la provincia de Alicante, de 1976. En estos momentos se encuentra en fase de exposición al público el Avance de Planeamiento del nuevo P. G. O. U. que marcará las normas urbanísticas en los próximos años.

Uno de los mayores problemas con los que se enfrenta el municipio es la falta de infraestructuras en varios sectores donde se han levantado bloques de apartamentos sin una red viaria capaz de drenar el tráfico que se acumula extraordinariamente en los meses estivales, dada la acusadísima estacionalidad del turismo en Torrevieja. El planteamiento de que las infraestructuras de cualquier tipo suponen un alto coste al municipio y que éstas aparecen subutilizadas diez meses al año, no justifica su inexistencia. Es más, en los años 1974-78, en los que se construyeron grandes conjuntos de bloques en sectores como la playa del Acequión, del Cura, etc..., en medio de la anarquía de construcción no se obligó a los promotores a realizar obras básicas de infraestructura tales como alcantarillado, red viaria, zonas verdes, aparcamientos, etc..., sino que se dejó especular con el suelo hasta las últimas consecuencias. Por contra, las zonas afectadas por Planes Parciales no han tenido en general tantos inconvenientes y su planificación puede decirse que es aceptable.

Para actuar contra la especulación el Avance contempla las descalificaciones del suelo urbano en aquellos sectores que cuentan con Planes Parciales aprobados pero en los que no se han realizado las obras. Asimismo, el ayuntamiento ha elaborado un Proyecto de Delimitación de suelo urbano.

De entre los objetivos básicos establecidos en el Avance conviene destacar por su trascendencia en la morfología urbana:

-La creación de una red arterial urbana, alejada de la costa y paralela al mar, con penetraciones perpendiculares almismo, con lo que se pretende conseguir una morfología urbana policéntrica, desarrollada linealmente a lo largo de la costa.

-Evitar la circulación intensa a lo largo del frente de mar.

-Frenar la expansión desordenada del diseminado en las inmediaciones de las salinas a la vez que conseguir una ocupación intensiva y controlada del espacio en la franja costera.

-Proteger los espacios de interés natural y agrícola.

-Evitar la contaminación de las aguas superficiales y especialmente las subterráneas, por la falta de alcantarillado adecuado.

Con el fin de evitar la congestión del tráfico, se ha diseñado una red viaria estructurada sobre la N-332, desdoblada con una carretera de circunvalación exterior y otra de circunvalación interna que efectuará el papel de drenaje de [133] la actual carretera de la costa, accediendo a ésta mediante ramales perpendiculares.

La nueva clasificación del suelo se establece entre Suelo Urbano (SU, 966 ha), Suelo Urbanizable (SB, 729 ha) y Suelo No Urbanizable (SN, 5.543 ha).

En el litoral, la complejidad de circunstancias que en él operan, como la degradación del medio ambiente, necesidades de creación de infraestructura, etc..., obliga a elaborar un Plan Especial en un plazo de dos años entre cuyos objetivos figurará evitar la muralla de edificación que en el futuro impida el proceso de crecimiento en profundidad.

Se establece pues la necesidad de una planificación, con un equilibrio entre el turismo y las demás actividades litorales (pesca, salinas y agricultura), frente a un desarrollo caótico y desordenado.

\section{INCIDENCIA DE LAS ACTIVIDADES TURÍSTICAS}


El extraordinario desarrollo del turismo de masas provoca una acusada especialización turística que, por otra parte, tal y como señala Dalmasso ${ }^{20}$, introduce un elemento de vulnerabilidad en la economía, por tratarse de una actividad muy sensible a la coyuntura.

El negocio turístico produce un importante trasvase de mano de obra desde el sector primario, esencialmente, hacia las actividades terciarias y al subsector construcción, que experimentan un acelerado crecimiento en muy pocos años. En efecto, dado que el turismo es una actividad intensiva en mano de obra, se produce una creciente oferta de puestos de trabajo en la construcción y en la hostelería, sobre todo, lo que motiva el abandono del subsector de la pesca por un elevado contingente de activos, a los que se unen los procedentes de núcleos rurales próximos. La construcción es el subsector que más crece y que, a su vez, favorece el crecimiento de otros subsectores como materiales de construcción, transformados metálicos, carpintería, vidrio, etc..., que experimentan los efectos vinculantes de la inversión turística (Hirschman). Pero la estacionalidad del fenómeno turístico plantea desde el primer momento un problema de inestabilidad laboral y falta de profesionalización: un elevado índice de activos presta su servicio en la hostelería durante dos meses al año, mientras el resto del año lo hace en otro subsector.

La actividad económica del municipio, a excepción de la explotación salinera, gira casi en su práctica totalidad en torno al turismo, actividad dominante que orienta los demás sectores a sus exigencias. La ciudad se expone a los riesgos de un «monocultivo turístico» cuyas desastrosas consecuencias se pusieron de manifiesto a partir de 1979-80, cuando la actividad constructora entra en crisis y un gran número de activos quedó en situación de paro, con una repercusión obvia en todos los subsectores vinculados. [134]

El Padrón de Contribución Industrial es una fuente para el conocimiento de los establecimientos y actividades turísticas en el municipio pero, a la hora de abordar este tipo de análisis, se plantea el problema de diferenciar los establecimientos y actividades que están destinados a hacer frente a las necesidades de la población permanente de aquellos otros establecimientos orientados a la población que sólo reside temporalmente. En principio se sabe que un elevado índice de los establecimientos y actividades se orientan a los dos tipos de clientela en proporciones diferentes, lo cual dificulta aun más la diferenciación, pero la misma estacionalidad del fenómeno turístico nos facilita un primer criterio de estudio, ya que un buen número de establecimientos sólo abre sus puertas en verano, lo cual confirma su carácter preeminentemente turístico.

Del total de 130 establecimientos que se engloban en el epígrafe de hostelería (cafeterías, bares, restaurantes, hoteles, pensiones, fondas, heladerías), alrededor del 50\% tienen una actividad temporal, que se reduce a los meses de junio, julio, agosto y septiembre (en algún caso se trabaja la Semana Santa en función de la gran afluencia de visitantes que se produce). Se constata además que estos establecimientos de actividad temporal se ubican en las urbanizaciones de la periferia o a lo largo del eje costero, en la carretera a La Mata o en la salida hacia Cartagena, es decir, en los sectores con mayor porcentaje de viviendas no ocupadas principalmente.

Por lo que se refiere a los establecimientos y actividades restantes, dada la mayor complejidad para establecer una diferenciación, se han considerado los que presentan una clara dedicación al turismo, como venta de terrenos, agencias de viajes, artículos de regalo, alquiler de coches, etc..., con los que se obtiene una cifra de 52 establecimientos.

Al hablar de las repercusiones económicas del turismo no se puede eludir la importancia que ha tenido tradicionalmente el alquiler de las casas de habitación permanente para el veraneo, actividad que permitía a muchas familias obtener unos ingresos complementarios a cambio de

${ }^{20}$ DALMASSO, E., Les activités tertiaires, leur rôle dans l'organisation de l'espace, París, CDU y SEDES réunis, 1976, pág. 117. 
sacrificar su veraneo, como se constata en otros lugare ${ }^{21}$. Este sistema se encuentra hoy en clara regresión y adopta nuevas formas tales como el alquiler de apartamentos y chalés, un negocio que en gran parte se escapa de las manos de la población del municipio.

En función del turismo, la venta ambulante cobra también una gran importancia, de forma que el mercadillo que se celebra cada viernes y cuyo número de puestos oscila en torno a los 490, en verano ronda los 850 , a la vez que se aprecia un considerable aumento de los puestos dedicados a la venta de objetos para turistas (artesanía, bisutería, cerámica, bolsos, etc...), muchos de aquéllos con carácter itinerante frente a los de constante asiduidad. Pero los [135] ambulantes mejor representados son los de confección $(21,2 \%)$ y zapatos $(15,3 \%)$, cuyo número se incrementa sensiblemente en el verano. En este sentido hay que señalar que Torrevieja centraliza en los meses de junio a septiembre los servicios comerciales de todo un amplio espacio cuyos límites se extienden a veces más de 20 kilómetros en el entorno del núcleo, sobre todo en dirección sur, a lo largo de la N-332, ya que se convierte en centro funcional de todas las urbanizaciones del litoral oriolano, a lo que se añade la atracción exótica y de ganga que el mercadillo ejerce sobre un gran número de turistas, hasta de La Manga del Mar Menor. Es más, se ha llegado a montar un sistema de viajes organizados para acudir al mercado, cuya trascendencia económica sobre comercios y establecimientos hoteleros (bares y restaurantes esencialmente) es de una considerable importancia, a pesar de que esto sólo se produce una vez por semana.

Las actividades del ocio (feria, festivales, actividades folklóricas...) contribuyen a acentuar la centralidad del núcleo, con especial intensidad durante los fines de semana.

La nueva jerarquización y articulación espacial que crea el turismo durante los meses estivales tiene su reflejo en las vías de comunicación (N-332 y A-332 especialmente) que registran una saturación extraordinaria en las horas punta de acceso al centro comercial.

El turismo tiene también unos elevados costes sociales y económicos. Ya se ha hablado del problema de la especulación del suelo, a lo que se une la escasez de otros medios naturales como el agua y la degradación de la integridad medioambiental. Desde el punto de vista social, se imponen nuevos ritmos de vida que acaban degradando los valores culturales y tradicionales de la población, a lo que se ha unido la desaparición de la forma de hábitat tradicional. Tal y como señalan Cazes y Reynaud, la implantación turística aparece como una proyección degenerada de los modos de vida urbanos ${ }^{22}$. [136]

${ }^{21}$ ROSSELlÓ VERGER, V. M., Mallorca: el Sur y Sureste, Palma de Mallorca, Cámara Oficial de Comercio, Industria y Navegación, 1962, pág. 491.

${ }^{22}$ CAZES. G., y REYNAUD, A., «Presentation», Travaux de l'Institut de Géographie de Reims, números 13-14, 1973, pág. 4. 


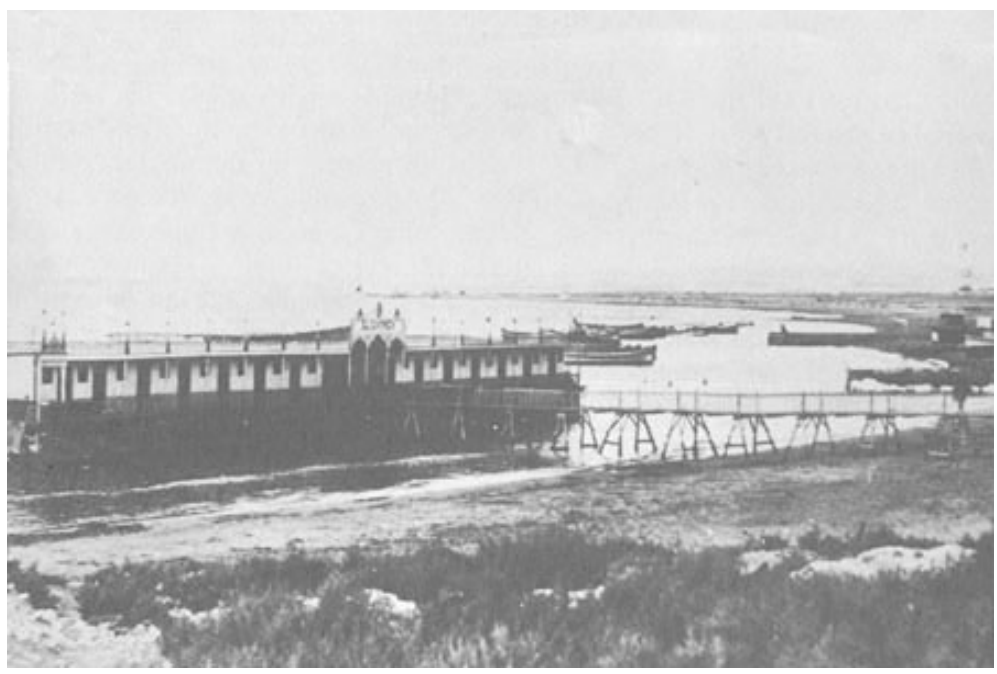

FOTO 1. La playa del Acequión con el balneario de El Carmen a principios de siglo.

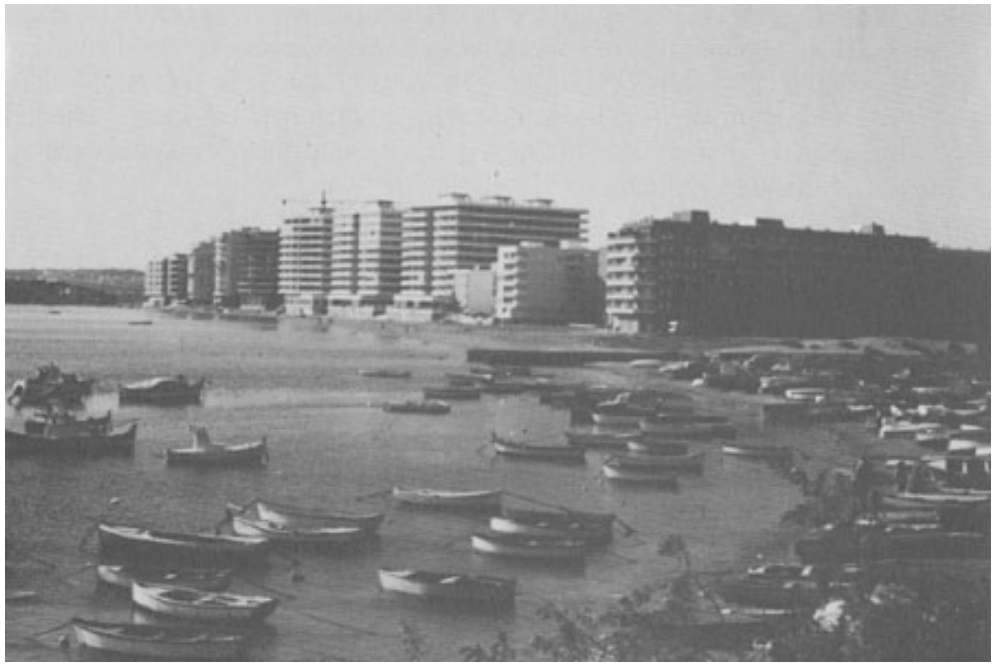

FOTO 2. La playa del Acequión en 1983. Obsérvese el murallón de edificaciones creado por el turismo y las segundas residencias. [137] 


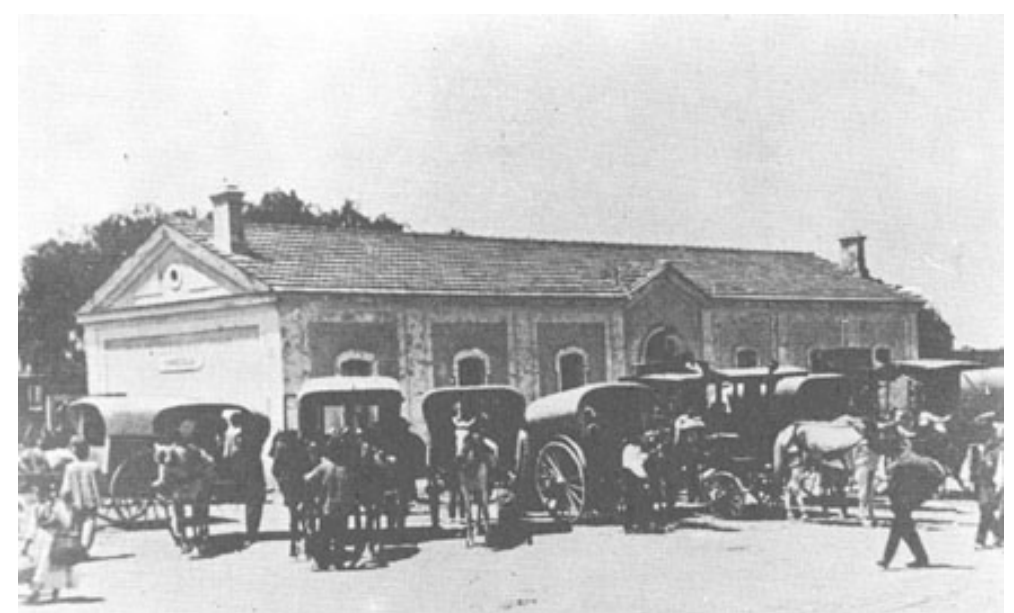

[138] 


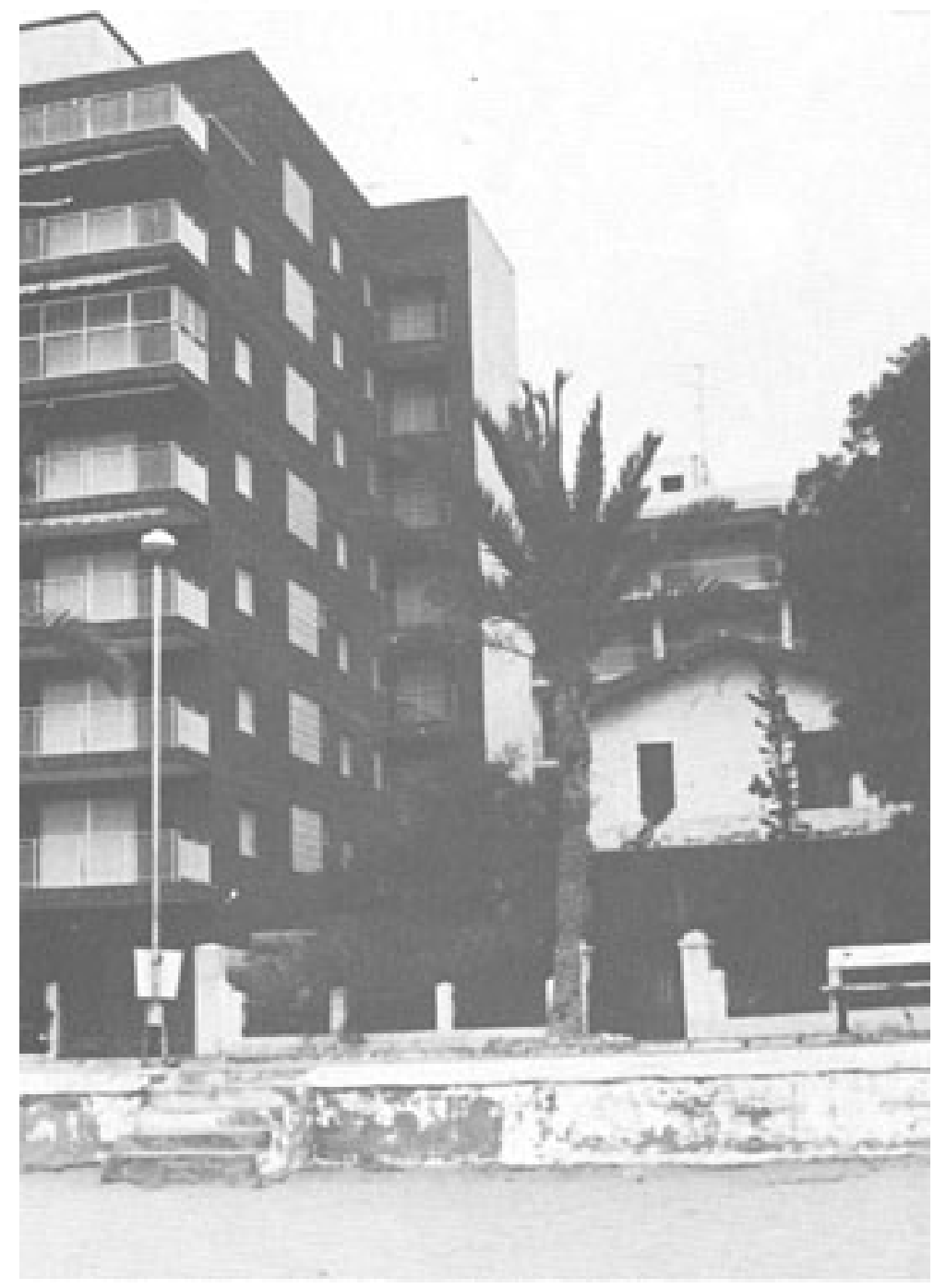

FOTO 4. El contraste entre las residencias del veraneo tradicional (década de 1920-30) y los bloques de apartamentos levantados en los últimos años es evidente en la playa del Cura. 